\title{
The global divide in data-driven farming
}

\author{
Zia Mehrabi $\oplus^{1,2,3 凶}$, Mollie J. McDowell $\oplus^{3}$, Vincent Ricciardi $\oplus^{1,2}$, Christian Levers $\oplus^{1,2,4}$, \\ Juan Diego Martinez $\mathbb{1}^{1,2}$, Natascha Mehrabi ${ }^{5}$, Hannah Wittman ${ }^{2,3}$, Navin Ramankutty ${ }^{1,2}$ and \\ Andy Jarvis 6
}

Big data and mobile technology are widely claimed to be global disruptive forces in agriculture that benefit small-scale farmers. Yet the access of small-scale farmers to this technology is poorly understood. We show that only 24-37\% of farms of $<\mathbf{1 h a}$ in size are served by third generation (3G) or 4G services, compared to $\mathbf{7 4 - 8 0 \% ~ o f ~ f a r m s ~ o f ~}>\mathbf{2 0 0}$ ha in size. Furthermore, croplands with severe yield gaps, climate-stressed locations and food-insecure populations have poor service coverage. Across many countries in Africa, less than $\mathbf{4 0 \%}$ of farming households have Internet access, and the cost of data remains prohibitive. We recommend a digital inclusion agenda whereby governments, the development community and the private sector focus their efforts to improve access so that data-driven agriculture is available to all farmers globally.

( ) ata-driven interventions are widely suggested to be a disruptive force in global food systems $s^{1-5}$. The aim is to use big data and mobile technology to address issues as diverse as low crop yields ${ }^{6}$, poor human nutrition ${ }^{7}$, disease ${ }^{8}$ and climate adaptation $^{1}$. However, mobile network coverage, handset ownership and affordable mobile service subscriptions are necessary prerequisites to achieve these solutions. Although the footprints of mobile networks and mobile phone ownership have increased in recent years, and the costs of mobile data have declined ${ }^{9}$, substantial gaps in access remain. Nearly half of the world's population is estimated to still be without Internet access ${ }^{10}$. There is concern that this digital divide could stall the realization of human rights $^{11}$ and the Sustainable Development Goals of the United Nations (UN), particularly those relating to education, equity, health and well-being ${ }^{12}$.

We define data-driven farming as the use of data to augment decision-making in farming systems and thus improve food system outcomes such as crop yields, profits, environmental sustainability and food security. The potential for data-driven farming to improve food systems has recently expanded due to advances in three key areas: data generation (for example, in mobile devices, field sensors, satellites and 'farmers as sensors'), data processing and predictive analytics (for example, by using big data stacks, machine learning and deep learning), and human-computer interactions (that is, human-centric approaches to create experiences that improve the ease and use of insights through voice, text and images). Data-driven farming is promoted in areas such as climate services ${ }^{13}$, digital extension ${ }^{14}$, precision agriculture ${ }^{3}$, market information systems ${ }^{15}$ and agricultural insurance ${ }^{2}$. There are many specific examples, including the IBM Watson Decision Platform for Agriculture, which uses performance geocomputation and a range of input data, such as high-resolution weather forecasts, for localized prescription farming and crop management ${ }^{16}$. Another example is the Nuru application of the UN Food and Agricultural Organization, which uses computer vision for in-field pest and disease diagnostics of major food security threats such as the damage caused by the fall armyworm ${ }^{17}$.
Recent synthesis has estimated that mobile-phone-based digital extension and price information systems in sub-Saharan Africa and India, some of which are data-driven, can modestly improve crop yields, increase adoption of recommended inputs, and raise farmer profits ${ }^{14}$. Basic benefits of the use of mobile technologies have also been reported in healthcare; for example, where improvements in patient outcomes and reduced healthcare costs have been documented ${ }^{18}$. However, it is poorly understood how the differential access to mobile technologies in farming communities might limit the vision for achieving data-driven farming, health and nutrition globally $^{19}$. In particular, donors, governments and research organizations lack sufficient understanding of the spatial distribution of data services across farms, and how existing services intersect with farms that have the greatest need for support and areas which contain the most food-insecure populations ${ }^{20}$. This lack of understanding of the baseline for data-driven farming limits our ability to assess the feasibility, scalability and probable impact of investment in digital technology projects and interventions in food systems across the world.

Here, we report a global baseline assessment of the state of mobile coverage and access to data services in farming. We use the coverage of mobile services as a measure of availability, which is the basic infrastructural backbone needed for scaling data-driven solutions. We examine how this availability intersects with opportunities for raising productivity and delivering financial, climate and healthcare services. We then assess subnational patterns in mobile phone and Internet access across non-farming and farming populations, for a subset of countries for which subnational data are available. In these countries are found $75 \%, 88 \%$ and $46 \%$ of all farming households in Africa, Latin America and the Caribbean, and Asia, respectively. We consider our results within the context of the current needs for closing the digital divide in agriculture on a global scale.

\section{Availability gaps}

Our analysis shows that second generation (2G) services (suitable for voice and short message services (SMSs)) cover $84 \%$ of croplands globally, but this coverage is $62 \%$ for third generation $(3 \mathrm{G})$

'The UBC School of Public Policy and Global Affairs, University of British Columbia, Vancouver, British Columbia, Canada. ${ }^{2}$ Institute for Resources, Environment and Sustainability, University of British Columbia, Vancouver, British Columbia, Canada. ${ }^{3}$ Center for Sustainable Food Systems, University of British Columbia, Vancouver, British Columbia, Canada. ${ }^{4}$ Department of Computational Landscape Ecology, Helmholtz Centre for Environmental Research - UFZ, Leipzig, Germany. ${ }^{5}$ Vancouver, British Columbia, Canada. ${ }^{6} \mathrm{CGIAR}$ Research Program on Big Data in Agriculture, International Center for Tropical

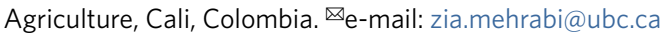




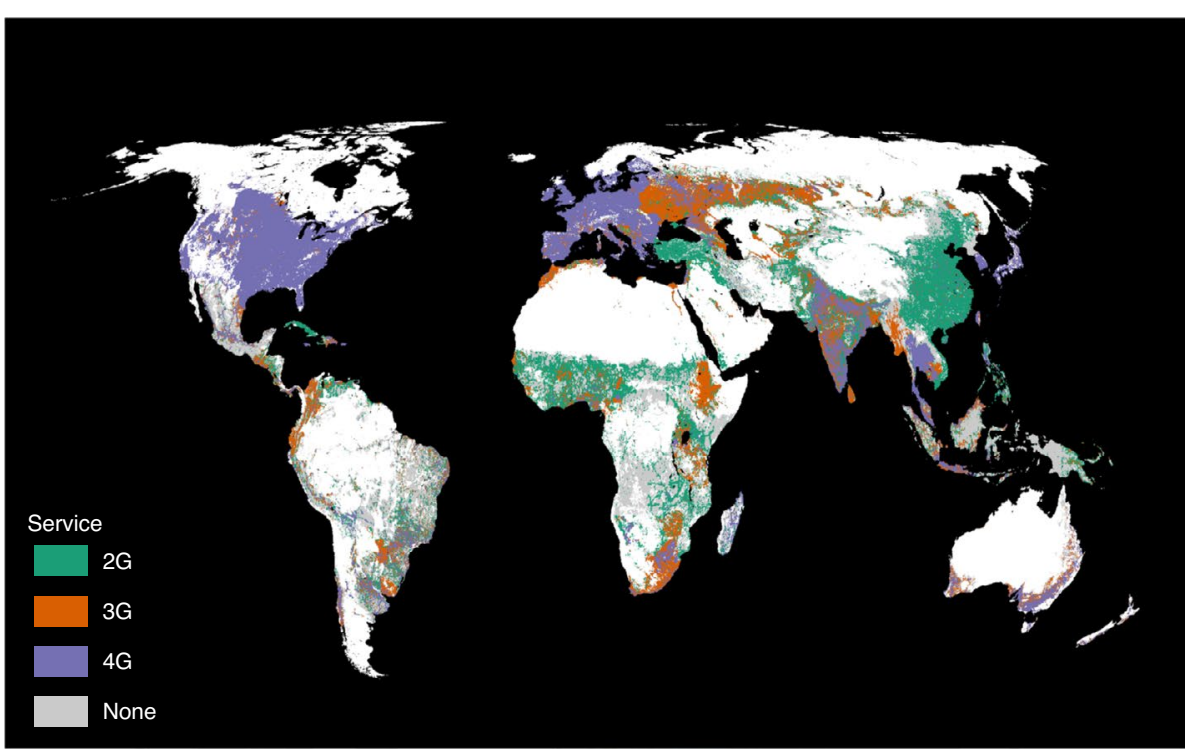

b

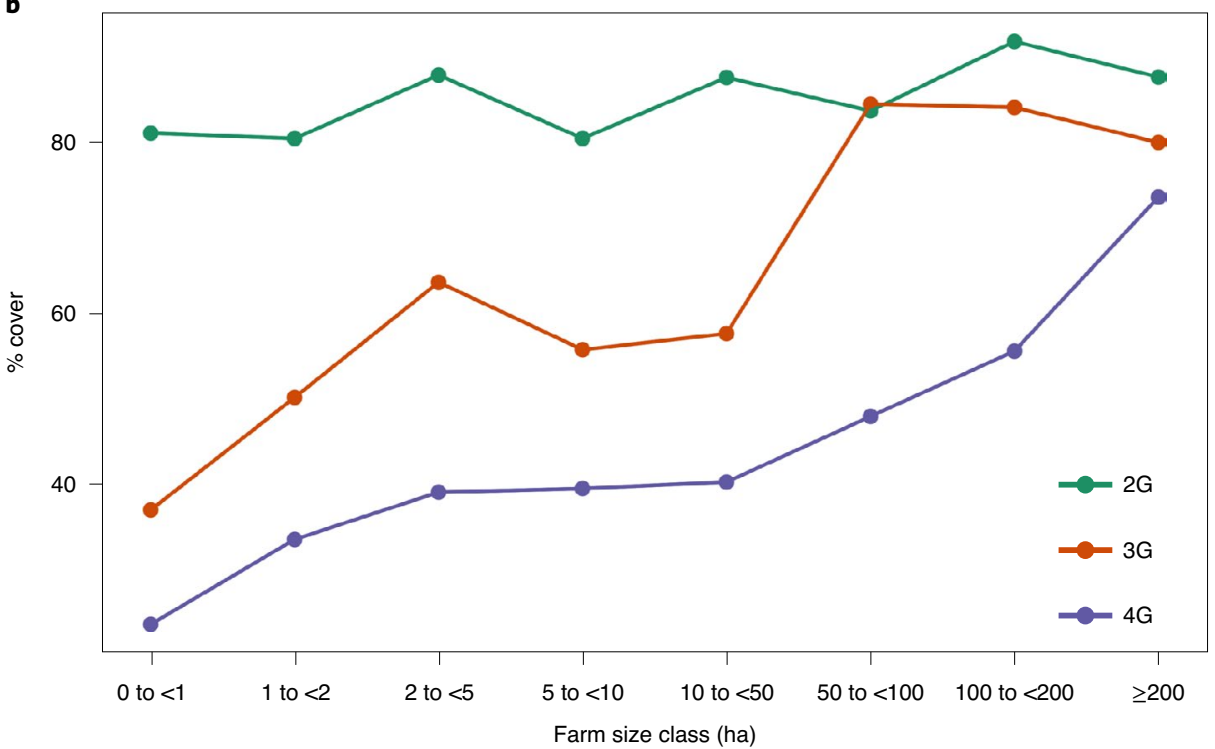

Fig. 1 | The coverage of mobile services across global croplands. a, A global map showing 2G, 3G and 4G mobile coverage across croplands. Croplands not covered by any service are shown in grey. $\mathbf{b}$, Percentage of global coverage across farm size classes. Cropland data ${ }^{37}$ are centred on the year 2000. Coverage data are from April 2018 and were obtained from Mosaik Solutions (see Methods).

and $42 \%$ for $4 \mathrm{G}$ services (Fig. 1a). This pattern of unequal coverage is even more marked across farm size classes. Small farms have disproportionately slower services available to them than large farms (Fig. 1b). Globally, only $37 \%$ and $24 \%$ of farms of $<1$ ha receive $3 \mathrm{G}$ and $4 \mathrm{G}$ services, respectively, whereas $80 \%$ and $74 \%$ of farms of $>200$ ha receive $3 \mathrm{G}$ and $4 \mathrm{G}$ services, respectively.

Spatial heterogeneity in coverage is important. High-speed (that is, $3 \mathrm{G}$ and $4 \mathrm{G}$ ) services are predominant in North America and Europe, whereas large coverage gaps exist in sub-Saharan Africa. Across the African continent, network coverage on cropland is only $33 \%$ for $3 \mathrm{G}$ and $9 \%$ for $4 \mathrm{G}$ services, and in Asia, it is $46 \%$ for $3 \mathrm{G}$ and $29 \%$ for $4 \mathrm{G}$ services. However, coverage in Asia varies by country. For example, the majority of India and Thailand are covered by $3 \mathrm{G}$ and $4 \mathrm{G}$ services, whereas large gaps exist in China, Vietnam and Mongolia (Fig. 1a).

In terms of high-speed network coverage of areas with the greatest need for support, we find that, globally, coverage in areas affected by nitrogen-deficient soils and severe yield gaps is around $60 \%$ for $3 \mathrm{G}$ and $22 \%$ for $4 \mathrm{G}$ services. Coverage in areas that are most dependent on rainfall for crop production is $71 \%$ for $3 \mathrm{G}$ and $54 \%$ for $4 \mathrm{G}$ services. Coverage in arid croplands (environments that receive $<250 \mathrm{~mm}$ annual rainfall) is $37 \%$ for $3 \mathrm{G}$ and $17 \%$ for $4 \mathrm{G}$ services (Table 1). Coverage gaps pose important obstacles for developing data-hungry nutrient advisories, climate services and financial services that need mobile Internet access.

We also assessed cross-cutting themes of food insecurity and the incidence of communicable diseases, which together represent compounding factors that increase population vulnerability alongside low crop productivity and climate stressors. These themes underpin efforts to develop mobile health services for rural populations. We find that, of individuals affected by food insecurity globally (as measured by the prevalence of childhood stunting $\left.{ }^{21}\right), 61 \%$ are served by $3 \mathrm{G}$ and $45 \%$ are served by $4 \mathrm{G}$. In Africa, the numbers are particularly low (52\% and $22 \%$ for $3 \mathrm{G}$ and $4 \mathrm{G}$, respectively). Globally, 
Table 1 | Current mobile coverage in areas of agriculture and health that may benefit from mobile interventions

\begin{tabular}{|llll} 
Dimension & $\begin{array}{l}\text { 2G coverage } \\
\text { (\%) }\end{array}$ & $\begin{array}{l}\text { 3G coverage } \\
\text { (\%) }\end{array}$ & $\begin{array}{l}\text { 4G coverage } \\
\text { (\%) }\end{array}$ \\
\hline Mobile agriculture (area) & & & \\
\hline Yield gaps & 82 & 61 & 21 \\
\hline Nitrogen deficiency & 79 & 60 & 22 \\
\hline Rainfall reliance & 93 & 71 & 54 \\
\hline Extreme aridity & 80 & 37 & 17 \\
\hline Mobile health (people) & & & \\
\hline Food insecurity & 93 & 61 & 45 \\
\hline Infected with P. falciparum & 82 & 37 & 17
\end{tabular}

of individuals with malaria (those infected with Plasmodium falciparum), only $37 \%$ have access to $3 \mathrm{G}$ services and $17 \%$ to $4 \mathrm{G}$ services. This lack of coverage for at-risk populations poses serious concerns not only for the development of mobile services for populations affected by existing nutritional burdens and diseases, but also for the response of wider populations to food security threats and health impacts of emerging diseases, including COVID- 19.

\section{Access gaps}

Our analysis highlights differences in household ownership of mobile handsets. Although ownership of mobile phones by farming households in many locations throughout Asia and Latin America is at, or close to, $100 \%$, we find that mobile phone ownership within African countries lags behind that of the rest of the world (Fig. 2a). For example, in Angola, the Democratic Republic of the Congo (DRC), Madagascar and Burundi, the subnational averages for mobile phone ownership (for any kind of device) by farming households range between $34 \%$ and $51 \%$ (Fig. 2a). The numbers are higher in other African countries, such as Malawi, Mozambique, Rwanda, Chad and Sierra Leone, nevertheless, more than $30 \%$ of farming households in these countries still do not own a mobile phone.

Furthermore, in some countries, farmer access to mobile phones is similar to, or exceeds, that of non-farmers, whereas in other countries farmers are less likely to own mobile phones than non-farmers. For example, in Angola, Madagascar and the DRC, ownership in non-farming populations is $24 \%, 12 \%$ and $11 \%$ (percentage points) higher, respectively, than in farming populations (Fig. 2a). Other studies have pointed to a gender gap in mobile phone ownership, with women being 14\% less likely to own one (and 38\% less likely in South Asia). This means that there is not only a divide between farming and non-farming populations, but also between men and women within households ${ }^{22}$, and this poses a particular concern for inclusivity of interventions relating to primary care and child nutrition.

It is well known that Internet access across countries in Asia, Latin America and Africa still lags behind that in other regions of the world such as North America and Europe, but we show that Internet access also varies at the subnational level, and importantly, between farming and non-farming populations. Internet access is generally much lower than mobile handset ownership. For example, the average percentage of farming households with Internet access is low in India (31\%), and even lower in Pakistan (21\%) and Tajikistan (12\%). Similarly, it is $25 \%$ in Mexico, $14 \%$ in Bolivia and just $5 \%$ in Haiti. Furthermore, with the exception of Côte d'Ivoire, Ghana and Namibia, we find that Internet access is less than $40 \%$ of households, on average, for the remaining African countries included in our analysis (Fig. 2b). In Costa Rica, Brazil and Angola, the gap between Internet access for farmers and for the rest of the population at the subnational level is on average $19 \%, 15 \%$ and $11 \%$, respectively (Fig. 2b). Farmers in these locations are bearing the burden of the digital divide resulting from unequal Internet access, which is unaccounted for in aggregated statistics.

Farmers, particularly smallholders, not only depend on the installation of mobile networks and owning mobile handsets, but they must also pay for data access. However, the access problems of people living in poverty are often masked because the often-cited average costs of data are based on mean incomes ${ }^{23}$. We disaggregated the costs of accessing data for ten income groups across 83 countries in Africa, Asia, and Latin America and the Caribbean, and show that, for the poorest $10 \%$ of the population, the cost of fully engaging in the digital economy is still prohibitively high (Fig. 3). The situation is worst for some countries in sub-Saharan Africa (the Central African Republic, the DRC, Guinea-Bissau, Chad, Sierra Leone, Togo, Madagascar and Malawi) where the cost of a basic $1 \mathrm{~GB}$ monthly plan ranges from as much as $64 \%$ to $188 \%$ of the annual income of the poorest $10 \%$ of the population. Although incomes have risen and average Internet access costs have declined in Africa in recent years, the cost of a basic 1 GB monthly plan in the last quarter of 2018 was still estimated to be more than a quarter of the annual income of the poorest $10 \%$ in countries of the continent (Fig. 3 inset). To put this into perspective, the 2025 target adopted by the Broadband Commission for Sustainable Development is that entry-level broadband should be made available in all countries at $2 \%$ of gross national income per capita ${ }^{24}$.

\section{Key recommendations}

Our analyses show that substantial gaps still exist in the availability of, and access to, data services for the world's farming populations. These gaps preclude the participation of many smallholders in the latest technological innovations and need to be addressed if we are to move towards fairer, more inclusive and equitable food systems globally. Here, in light of these findings, we outline some key recommendations for governments, agricultural development organizations, funders, entrepreneurs and academics.

Invest in 'last-mile infrastructure' innovation. Closing the coverage gap will require continued innovation in three critical areas of last-mile infrastructure: energy (for example, moving from diesel generators to cost-efficient fuel cell generators or solar energy $)^{25}$, cell towers (for example, installing 'light towers' with reduced complexity or deployment costs) and backhaul technologies (for example, complementing fibre optics with innovations such as scalable microwave 'pay-as-you-grow' solutions). Although efforts to bridge coverage gaps using these, as well as other more radical cross-cutting innovations that use satellites and wide-area deployments-such as Google's project Loon, OneWeb, or SpaceX's Starlink-exist, their success remains to be proven in many farming landscapes in the world, and particularly in the African continent. Such investments need to be supported by policies that lower regulatory friction, increase open competition and reduce capital risks for the private sector, especially in the early stages of deployment.

Increase handset affordability. Business model innovation will be required to provide handsets that are both affordable and capable of a seamless broadband experience. Existing business models include upfront payment for handsets (which is not possible for the poorest sectors of society), asset financing (which allows access to credit but has default risk) and third-party provision (by governments, non-governmental organizations and private companies that derive value from the user, but is often not sustainable). Average device costs in emerging markets remain high (approximately US $\$ 100)^{26}$. Affordability should be addressed from two perspectives. On the one hand, incomes need to be increased by financing business 


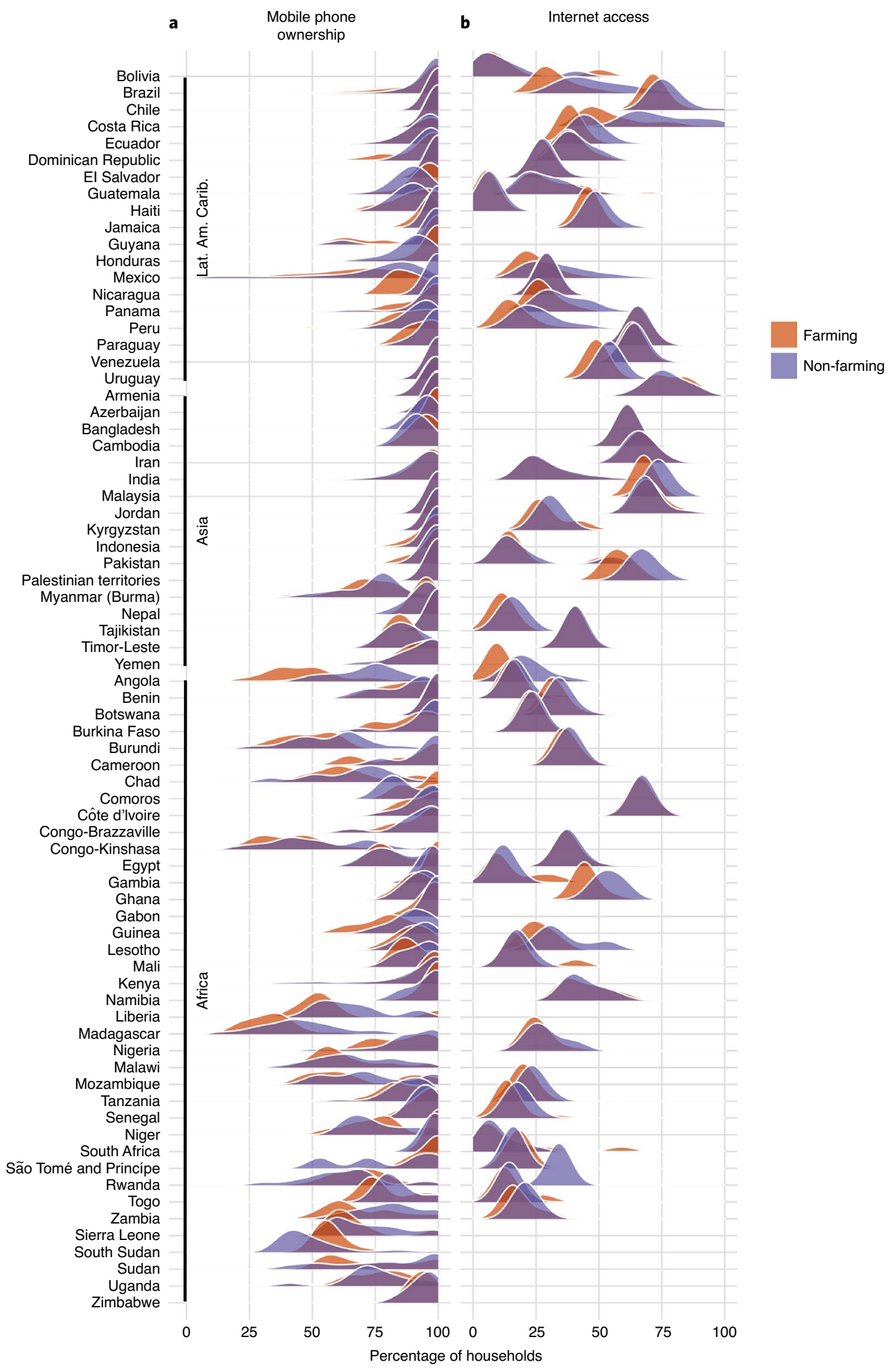

Fig. 2 | Mobile phone ownership and Internet access in farming households. a, Subnational distributions of the percentage of mobile phone ownership in non-farming and farming households across Africa, Asia, and Latin America and the Caribbean ( $n=5,429$ administrative units). b, Subnational distributions of the percentage of non-farming and farming households that have Internet access $(n=4,905$ administrative units). All data are centred in 2018. Lat. Am. Carib., Latin America and the Caribbean.

growth and job creation, particularly for women and underserved groups in rural communities ${ }^{27}$. On the other hand, device costs need to be reduced by blending business models that create value between state actors, financial institutions, mobile network operators, device manufacturers and content providers ${ }^{24}$. Here, national agricultural research services and research for development organizations can 


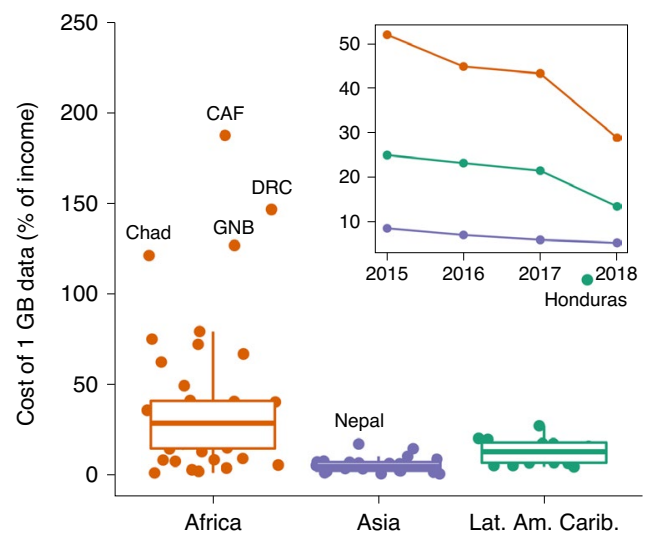

Fig. 3 | The cost of mobile data for the poorest $10 \%$ of people. The cost of $1 \mathrm{~GB}$ of data per month as a percentage of annual income in Africa, Asia, and Latin America and the Caribbean in 2018. CAF, Central African Republic; GNB, Guinea-Bissau; Lat. Am. Carib., Latin America and the Caribbean. Inset, a time series of the median cost of $1 \mathrm{~GB}$ of data from 2015-2018 for Africa, Asia, and Latin America and the Caribbean. The vertical axis label of the inset graph is the same as for the main graph.

play important roles to assist in the design of localized solutions for farming populations.

Make data access universal. Innovation in infrastructure and business models can help to reduce the cost of deploying the last-mile infrastructure, which, in turn, should be reflected in the price of data for farmers. However, further actions will probably be required to ensure accessibility to all. Given the importance of mobile technology, to bring everyone online globally currently translates to universal access to mobile broadband. In addition, because the poorest farmers are unable to buy data, mobile broadband must be made a public good. Although a public and donor-funded Universal Service and Access Fund has been proposed to connect the poorest households in Africa to the Internet ${ }^{24}$, universal access should be made available to farmers globally.

Identify interim solutions. SMS-based advisories and alerts, and interactive voice response services that can run on low-end handsets, even if jointly owned or shared between community members, offer an important opportunity for addressing bundled issues of productivity, market connectivity, financial transfers, credit access, input use and within-season management, across large areas of farming landscapes globally ${ }^{2,14,28}$. These lean front-end solutions can be built on sophisticated back-end services that interface with the Internet and integrate remote sensing, ancillary data sets, and mechanistic and statistical prediction tools ${ }^{2}$. These interim solutions are essential for participation and inclusion, given current availability and access patterns.

Operationalize these findings. This baseline analysis assesses the digital divide in farming and regular operational updates will be required to track progress in access and availability of information and communications technology (ICT)-enabled solutions for agriculture. However, additional metrics, from availability and access to utilization, are also needed. Utilization depends on capacity building, skills transfer, digital literacy, cultural appropriateness of services and the agency to use services, particularly across ages and genders. We recommend core public research funding for this effort so that entrepreneurs, philanthropists and academics can better target their data-driven farming interventions, and so that the benefits of these interventions can be transparently assessed for positive farming and population health outcomes.

The idea of a technology revolution in agriculture has captured the minds of-and has secured funding from-donors, governments, national agricultural research services, development organizations, academic institutions and countless industry start-ups in recent years ${ }^{1-5}$. This vision is currently hindered by gaps in connectivity for farming populations. Emerging technologies such as $5 \mathrm{G}$ promise even more capabilities ${ }^{29}$, but the benefits for data-driven farming can never be fully realized as long as poor farmers are left behind ${ }^{19}$. A re-ignition of international efforts to deliver agricultural research for development is needed, this time not for the exchange and delivery of advanced seeds but for the exchange and delivery of data. This effort requires a fresh outlook, learning from the failures of previous revolutions in agriculture ${ }^{30}$, putting co-creation, knowledge sharing and farmer empowerment at the core, and seeking solutions that harmonize across the Sustainable Development Goals, particularly those related to education, gender inclusion, and access to water and energy ${ }^{25,31}$. The work presented here may provide a step in that direction and allows for the design of more targeted interventions for all those invested in solving farming problems by using data.

\section{Methods}

Details of the methods underlying specific components of this study are given below.

Coverage gaps. For the mobile service availability layers, we used a geographical information system data set, developed by Mosaik Solutions, on global mobile network coverage in 2018 for 910 entities running 2,391 networks in 229 countries and territories, and representing $2 \mathrm{G}$ (CDMA, 1XRTT, GSM, GPRS, EDGE), 3G (EVDO, UMTS, HDPA/+) and 4G (WiMax, LTE) services. This data set includes data provided directly by service operators, as well as data available on operator websites, in filings from regulatory bodies, and in the public domain, and is recognized as an industry standard reference ${ }^{32}$. Our map of smallholder farms was developed following the methods of ref. ${ }^{33}$ and updated with the crowd-sourced field sizes of ref. ${ }^{34}$. Global layers representing nutrient deficits for 17 major crops $^{35}$ and aridity (annual precipitation $<250 \mathrm{~mm}$ (ref. $\left.{ }^{36}\right)$ ) were intersected with cropland data $^{37}$ (for aridity) and relevant crop types ${ }^{38}$ (for nutrient deficiency) to create layers of cropland areas affected by each condition. Hotspots of yield gaps ${ }^{39}$ were computed using the 90th percentile of the ratio of yield gaps to yield potentials. Hotspots of rainfall-dependent croplands were computed using the 90th percentile of the ratio of green water to total water used for crop production from ref. ${ }^{40}$. We also assessed the cross-cutting themes of food insecurity and the incidence of communicable diseases. We estimated the number of people affected by food insecurity using maps ${ }^{21}$ that proxy food insecurity from the prevalence of childhood stunting, and we computed Africa-wide estimates using the updated data set of ref. ${ }^{41}$. We computed the number of people infected by $P$. falciparum using 2017 prevalence data from the Malaria Atlas Project (https://malariaatlas. $\mathrm{org} /$ ), and 2017 population estimates from LandScan ${ }^{42}$. For all layers, the coverage gap was computed as the proportion of each layer of cropland area and population classes covered by the $2 \mathrm{G}, 3 \mathrm{G}$ and $4 \mathrm{G}$ footprints.

Access gaps. We assessed access gaps in mobile phone ownership and Internet access across Asia, Africa, and Latin America and the Caribbean by compiling and harmonizing a sample of available subnationally representative micro-level data from the Demographic Health Surveys (https://www.dhsprogram.com), the Integrated Public Use Microdata Series (https://www.ipums.org), the Living Standards Measurement Study from the World Bank (https://www.worldbank.org/ en/programs/lsms), and country-specific agricultural censuses, general household surveys and family panel studies (see Data availability for our accompanying data set). We define a farming household as one that owns usable land for agriculture or one in which a household member works in an agricultural occupation. Household mobile ownership is defined as a household that owns at least one mobile phone, and Internet access is defined as a household that has access to the Internet, through any device. Our sample represents farming and non-farming household-level mobile ownership in 70 countries (38 in Africa, 15 in Asia and 17 in Latin America and the Caribbean) and in 5,429 subnational units (941 in Africa, 848 in Asia and 3,640 in Latin America and the Caribbean). Our sample also represents farming and non-farming Internet access in 48 countries (20 in Africa, 11 in Asia and 17 in Latin America and the Caribbean) and 4,905 subnational units (522 in Africa, 931 in Asia and 3,452 in Latin America and the Caribbean).

To centre mobile phone ownership data, we used available panel data sets of ownership (from 2005 to 2017), for countries in each region (ten in Africa, five in Asia and two in Latin America and the Caribbean). We estimated time-dependent percentage point differences in ownership within each region and for farming 
versus non-farming populations. We used the following shape-constrained generalized additive mixed model $^{43}$ :

$$
y_{i} \sim \operatorname{bin}\left(n_{i}, p_{i}\right)
$$

$$
\begin{aligned}
& p_{i}=\operatorname{logit}^{-1}\left(\alpha_{0}+\alpha_{1 \ldots m} r f_{i}+\sum_{l=1}^{q} \beta_{i l} b_{i l}\left(r f_{i} t_{i}\right)+\delta_{j[i]}\right) \\
& \text { for } i=1, \ldots n \text { observations }
\end{aligned}
$$

$$
\delta_{j}=N\left(0, \sigma_{\delta}^{2}\right) \text { for } j=1, \ldots J \text { countries }
$$

Here, $y_{i}$ is the observed number of households owning a mobile phone, $n_{i}$ is the number of households surveyed, and $p_{i}$ is the fraction of households that own a mobile phone; $b_{i l}\left(r f_{i} t_{i}\right)$ are the $l$ th monotonically increasing P-spline basis functions for year $(t)$ and the region and farming versus non-farming populations $(r f) ; q$ is the number of basis functions, $\beta_{i l}$ are the spline coefficients; $\delta_{j}$ are random intercepts (with variance $\sigma_{\delta}^{2}$ ) to account for non-independence of observations in countries; and $\alpha$ terms are fixed intercepts representing differences in fractional ownership for each $r f$ combination.

To centre Internet access data, we used national time-series data of individuals using the Internet (1990-2016) from the World Bank and the International Telecommunication Union (https://www.data.worldbank.org/indicator) to estimate time-dependent percentage point differences in access for each country between the observed years of sampling and a common focal year, using the following generalized additive model $^{44}$ :

$$
\begin{aligned}
& \qquad y_{i}=\operatorname{beta}\left(\mu_{i}, \phi\right) \\
& \mu_{i}=\operatorname{logit}^{-1}\left(\alpha_{0}+\alpha_{1 \ldots m} c_{i}+\sum_{l=1}^{q} \beta_{i l} b_{i l}\left(c_{i} t_{i}\right)\right) \\
& \text { for } i=1, \ldots n \text { observations }
\end{aligned}
$$

Where $y_{i}$ is the observed proportion of individuals with Internet access, $\mu_{i}$ is $\mathrm{E}(y), \phi$ is a precision parameter, $b_{i l}\left(c t_{i}\right)$ are $l$ th cubic-spline basis functions for year $(t)$ and country $(c)$, and $\alpha$ terms are fixed intercepts representing differences in percentage access for each $c$.

We centred access data on the year 2018 and used the percentages of farming and non-farming households who own mobile phones or have Internet access at each subnational unit within a country. For visual comparison of access within countries and between farming and non-farming populations, we fit Gaussian probability density functions to the mobile phone and Internet access metrics using subnationally representative sampling units (see Data and Code availability for raw time-centred data underlying these plots).

Cost of data. To identify the costs of data for people living in poverty, the cost of $1 \mathrm{~GB}$ of prepaid mobile access as a percentage of income was obtained from the Alliance for Affordable Internet (https://a4ai.org/) for 83 countries in Africa, Asia, and Latin America and the Caribbean. To disaggregate these data by income groups within each country, we used the income shares from the World Bank and re-computed the index of the Alliance for Affordable Internet using the income of the poorest decile of each country. To account for differences in sampling effort, we estimated the difference (a bias estimate) between the median regional cost of data in 2018 (the year with most complete coverage) and the median regional cost in 2018 when coverage equalled that of 2015-2018. We then bias corrected the time series by adjusting the median costs for the years 2015-2018 to known differences observed in 2018

\section{Data availability}

The data sets used and created in this study are archived at the Zenodo Public Repository: https://doi.org/10.5281/zenodo.4082121.

\section{Code availability}

All code for reproducing the results in this manuscript are archived at the Zenodo Public Repository: https://doi.org/10.5281/zenodo.4082121.

Received: 26 November 2019; Accepted: 22 September 2020; Published online: 2 November 2020

\section{References}

1. Tricarico, D. \& Darabian, N. mAgri-Weather Forecasting and Monitoring: Mobile Solutions for Climate Resilience (GSMA, 2016); https://go.nature. $\mathrm{com} / 37 \mathrm{lo} 5 \mathrm{eU}$

2. Information and Communication Technology (ICT) in Agriculture: a Report to the G20 Agricultural Deputies (FAO, 2017).

3. King, A. Technology: the future of agriculture. Nature 544, S21-S23 (2017).

4. World Bank Group Future of Food: Harnessing Digital Technologies to Improve Food System Outcomes (World Bank, 2019).
5. Kaka, N. et al. Digital India: Technology to Transform a Connected Nation (McKinsey Global Institute, 2019).

6. Eitzinger, A. et al. GeoFarmer: a monitoring and feedback system for agricultural development projects. Comput. Electron. Agric. 158, 109-121 (2019).

7. mNutrition: Addressing Hidden Hunger Through Mobile Messaging (CABI, 2017).

8. Asenso-Okyere, K., Asante, F. A., Tarekegn, J. \& Andam, K. S. A review of the economic impact of malaria in agricultural development. Agric. Econ. 42, 293-304 (2011)

9. Global Mobile Trends 2018. What's Driving the Mobile Industry? (GSMA Intelligence, 2018); https://go.nature.com/2T41ZW9

10. Measuring the Information Society Report 2018 Vol. 1 (ITU Publications, 2018).

11. Szoszkiewicz, Ł. Internet Access as a New Human Right? State of the Art on the Threshold of 2020. Adam Mickiewicz Univ. Law Rev. 8, 49-62 (2018).

12. ITU Council contribution to the 2019 High-Level Political Forum on Sustainable Development (HLPF) Revision 3 to Document CWG-WSIS\&SDG33/15-E (ITU, 2019).

13. Dobardzic, S. et al. 2019 State of Climate Services: Agriculture and Food Security. Report No. WMO-No. 1242 (World Meteorological Organization, 2019).

14. Fabregas, R., Kremer, M. \& Schilbach, F. Realizing the potential of digital development: the case of agricultural advice. Science 366, eaay3038 (2019).

15. Building Agricultural Market Information Systems: a Literature Review (FAO, 2017).

16. IBM AI and cloud technology helps agriculture industry improve the world's food and crop supply. IBM News Room (22 May 2019); https://go.nature. com/2T9nZiq

17. Nuru becomes African farmers' newest ally against Fall Armyworm. FAO (25 June 2018); http://www.fao.org/news/story/en/item/1141889/icode/

18. Free, C. et al. The effectiveness of mobile-health technologies to improve health care service delivery processes: a systematic review and meta-analysis. PLoS Med. 10, e1001363 (2013).

19. Mehrabi, Z., Jimenez, D. \& Jarvis, A. Democratize access to digital agronomy. Nature 555, 30 (2018)

20. Mattson, S. CIAT, World Bank and partners announce Digital Agriculture Country Profiles initiative. The Alliance of Biodiversity International and CIAT Blog (2019); https://go.nature.com/37xPHOj

21. FAO The State of the World's Land and Water Resources for Food and Agriculture: Managing Systems at Risk (Taylor \& Francis, 2011); https://doi. org/10.4324/9780203142837

22. Connected Women: Bridging the Gender Gap: Mobile Access and Usage in Low and Middle Income Countries (GSMA, 2015).

23. 2019 Affordability Report (A4AI, 2019); https://a4ai.org/affordability-report/

24. Connecting Africa Through Broadband: a Strategy for Doubling Connectivity by 2021 and Reaching Universal Access by 2030 (United Nations Broadband Commission for Sustainable Development, 2019).

25. Handforth, C. Closing the Coverage Gap: How Innovation Can Drive Rural Connectivity (GSMA, 2019).

26. Karlsson, M. et al. Accelerating Affordable Smartphone Ownership in Emerging Markets (GSMA, 2017).

27. Investing in Rural Livelihoods to Eradicate Poverty and Create Shared Prosperity (IFAD, 2017).

28. ICT in Agriculture (Updated Edition): Connecting Smallholders to Knowledge, Networks, and Institutions (World Bank, 2017).

29. Understanding 5G: Perspectives on Future Technological Advancements in Mobile (GSMA Intelligence, 2014).

30. Pingali, P. Green revolution: impacts, limits, and the path ahead. Proc. Natl Acad. Sci. USA 109, 12302-12308 (2012)

31. Maru, A. et al. Digital and Data-Driven Agriculture: Harnessing the Power of Data for Smallholders (Global Forum on Agricultural Research and Innovation, 2018).

32. 20th Mobile Wireless Competition Report (FCC, 2017).

33. Herrero, M. et al. Farming and the geography of nutrient production for human use: a transdisciplinary analysis. Lancet Planet. Health 1, e33-e42 (2017).

34. Lesiv, M. et al. Estimating the global distribution of field size using crowdsourcing. Glob. Change Biol. 25, 174-186 (2019).

35. West, P. C. et al. Leverage points for improving global food security and the environment. Science 345, 325-328 (2014).

36. Karger, D. N. et al. Climatologies at high resolution for the earth's land surface areas. Sci. Data 4, 170122 (2017).

37. Ramankutty, N., Evan, A. T., Monfreda, C. \& Foley, J. A. Farming the planet: 1. Geographic distribution of global agricultural lands in the year 2000. Glob Biogeochem. Cycles 22, GB1003 (2008).

38. Monfreda, C., Ramankutty, N. \& Foley, J. A. Farming the planet: 2. Geographic distribution of crop areas, yields, physiological types, and net primary production in the year 2000. Glob. Biogeochem. Cycles 22, GB1022 (2008). 
39. Mueller, N. D. et al. Closing yield gaps through nutrient and water management. Nature 490, 254-257 (2012).

40. Portmann, F. T., Siebert, S. \& Döll, P. MIRCA2000-Global monthly irrigated and rainfed crop areas around the year 2000: a new high-resolution data set for agricultural and hydrological modeling. Glob. Biogeochem. Cycles 24, GB1011 (2010).

41. Osgood-Zimmerman, A. et al. Mapping child growth failure in Africa between 2000 and 2015. Nature 555, 41-47 (2018).

42. Dobson, J. E., Bright, E. A., Coleman, P. R., Durfee, R. C. \& Worley, B. A. LandScan: a global population database for estimating populations at risk. Photogramm. Eng. Remote Sens. 66, 849-857 (2000).

43. Pya, N. \& Wood, S. N. Shape constrained additive models. Stat. Comput. 25 543-559 (2015).

44. Hastie, T. J. \& Tibshirani, R. Generalized additive models. Stat. Sci. 1, 297-310 (1986).

\section{Acknowledgements}

Z.M. and N.R. were funded by NSERC Discovery Grant RGPIN-2017-04648. Z.M., H.W., V.R. and N.R. were funded by Social Sciences and Humanities Research Council Insight Grant 435-2015-1364, and H.W. by the Canadian Institutes of Health Research grant ROH-115207. Z.M. and H.W. received funds from the VPRI Research Excellence Cluster on Diversified Agroecosystems of the University of British Columbia. C.L. was funded by the Horizon 2020 research and innovation programme of the Euroipean
Union under Marie Skłodowska-Curie grant agreement 796451. This work was implemented as part of the CGIAR Platform for Big Data in Agriculture, which is carried out with support from CGIAR Fund Donors and through bilateral funding agreements. For details, please visit https://www.cgiar.org/funders/.

\section{Author contributions}

Z.M. conceived, designed and led the study. N.M. helped with concept development. Z.M., H.W., N.R. and A.J. helped to secure funding. M.J.M., V.R., C.L. and J.D.M. compiled and developed the underlying data sets. Z.M. conducted the analysis and wrote the paper. All authors provided comments on the paper.

\section{Competing interests}

The authors declare no competing interests.

\section{Additional information}

Correspondence and requests for materials should be addressed to Z.M.

Reprints and permissions information is available at www.nature.com/reprints.

Publisher's note Springer Nature remains neutral with regard to jurisdictional claims in published maps and institutional affiliations.

(c) The Author(s), under exclusive licence to Springer Nature Limited 2020 